\title{
Nitric Oxide in the Retinotectal System: a Signal But Not a Retrograde Messenger During Map Refinement and Segregation
}

\author{
René C. Rentería ${ }^{1}$ and Martha Constantine-Paton ${ }^{1,2}$ \\ 1/nterdepartmental Neuroscience Program and '2Department of Molecular, Cellular, and Developmental Biology, \\ Yale University, New Haven, Connecticut, 06520
}

The role of nitric oxide (NO) as a mediator of synaptic plasticity is controversial in both the adult and developing brain. NO generation appears to be necessary for some types of NMDA receptor-dependent synaptic plasticity during development but not for others. Our previous work using several NO donors revealed that Xenopus laevis retinal ganglion cell axons stop growing in response to NO exposure. We demonstrate here that the same response occurs in tectal neuron processes bathed in the NO donor S-nitrosocysteine (SNOC) and in RGC growth cones to which SNOC is very locally applied. We show that NO synthase (NOS) activity is present in the Rana pipiens optic tectum throughout development in a dispersed subpopulation of tectal neurons, although effects of NO on synaptic function in a Rana pipiens tectal slice were varied. We chronically inhibited NOS in doubly innervated Rana tadpole optic tecta using L-N ${ }^{G}$ - nitroarginine methyl ester in Elvax. Despite significant NOS inhibition as measured biochemically, eye-specific stripes remained normally segregated. This suggests that NOS activity is not downstream of NMDA receptor activation during retinotectal synaptic competition because NMDA receptor activation is necessary for segregation of retinal afferents into ocular dominance stripes in the doubly innervated tadpole optic tectum. We conclude that NO has some signaling function in the retinotectal pathway, but this function is not critical to the mechanism that refines the projection and causes eye-specific stripes.

Key words: nitric oxide; nitric oxide synthase; development; synaptic plasticity; retinotectal projection; optic tectum; doubly innervated tectum; three-eyed frog
Since the first demonstration of neurotransmitter-evoked nitric oxide (NO) production in brain tissue (Garthwaite et al., 1988), NO has become an important candidate for the elusive retrograde messenger in synaptic plasticity to account for presynaptic alterations after postsynaptic NMDA receptor activation in both the mature and developing brain (Gally et al., 1990; Edelman and Gally, 1992). Recent results from genetic manipulations of type I and type III NO synthase (NOS) (Kantor et al., 1996; Son et al., 1996) have demonstrated that NO signaling pathways are critical for full expression of adult hippocampal CA1 long-term potentiation (LTP). Although the locus of LTP remains controversial, these experiments suggest a pathway through NOS for alterations in adult synaptic efficacy after NMDA receptor activation (Garthwaite, 1991).

During development of central projections, physical maintenance or retraction of presynaptic terminals appears linked to changes in synaptic strength. These developmental processes, like many examples of adult plasticity, depend on postsynaptic NMDA receptor activation (Constantine-Paton and Cline, 1998). Recent studies of three different visual projections reveal a role for NO as an activity-dependent retrograde messenger during some but not all NMDA receptor-dependent developmental pro-

\footnotetext{
Received Oct. 28, 1998; revised June 1, 1999; accepted June 4, 1999.
}

R.C.R. was a Howard Hughes Medical Institute Predoctoral Fellow. This work was supported by National Institute of Health Grant EY 06039 to M.C.-P. DETECTiVENT software and instruction were kindly provided by Dr. Norbert Ankri of the Institut Pasteur. We thank Matthew T. Colonnese for a critical reading of this manuscript, Mengia Rioult-Pedotti and John O'Reilly for collection of the physiological data, and Guillermo García-Cardeña for NOS assay instruction.

Correspondence should be addressed to Martha Constantine-Paton, Department of Molecular, Cellular, and Developmental Biology, Yale University, P.O. Box 208103, New Haven, CT 06520-8103.

Copyright @ 1999 Society for Neuroscience 0270-6474/99/197066-11\$05.00/0 cesses. In the ferret LGN, after retinal axon termination within eye-specific laminae, the afferents further segregate into $\mathrm{ON}$ and OFF sublaminae. This sublamination is NMDA receptordependent (Hahm et al., 1991) and is significantly reduced by NOS inhibitors (Cramer et al., 1996). However, in the mammalian visual cortex, shifts in ocular dominance columns induced by monocular deprivation (LeVay et al., 1975) are disrupted by NMDA receptor blockade (Kleinschmidt et al., 1987; Gu et al., 1989) but are not sensitive to inhibition of NOS activity (Reid et al., 1996; Ruthazer et al., 1996). Furthermore, ocular dominance column formation itself is not disrupted by NOS inhibition (Finney and Shatz, 1998). Finally, in the chick, the normal complete elimination of the ipsilateral retinotectal projection is partially disrupted by systemic NMDA receptor blockade (Ernst et al., 1999) and by systemic NOS inhibition (Wu et al., 1994).

The retinotectal projections to the doubly innervated optic tecta of three-eyed tadpoles respond to interocular synaptic competition by segregating into interdigitated rostrocaudal stripes of eye-specific terminals, reminiscent of mammalian ocular dominance columns (Law and Constantine-Paton, 1981). The induced stripes are believed to reflect a compromise between two processes that normally produce high-fidelity topographic maps: chemoaffinity cues that provide a tectal address and activitydependent cues that ensure that neighboring retinal ganglion cells (RGCs) terminate together in their target. Induced ocular dominance segregation and its maintenance during the growth of retinal axons that occurs during tadpole development is dependent on NMDA receptor activation (Cline et al., 1987). We have shown previously that RGC axonal growth cones are capable of responding to NO applied to retinal explants and growth cones in culture (Rentería and Constantine-Paton, 1996). Here, using NO 
donor application directly to the growing axons, we demonstrate that this growth modulation occurs locally at individual RGC growth cones. To determine whether this modulation of motility was downstream of NMDA receptor activity during synaptic competition, we examined eye-specific segregation in doubly innervated tecta after chronic NOS inhibition. We show here that this treatment has no effect on segregation. Thus, NO-mediated effects on RGC axon motility are not involved in the intact frog retinotectal neuropil during the NMDA receptor-mediated synaptic competition that produces the retinotopic map and stripes.

\section{MATERIALS AND METHODS}

\section{Materials}

Unless otherwise indicated, all reagents were obtained from Sigma (St. Louis MO).

\section{Normal tadpole breeding and care}

Rana pipiens tadpoles were lab-reared offspring of wild-caught males and gravid females from a commercial supplier (Hazen Co., Alburg, VT). Ovulation induction and egg fertilization were performed using standard procedures. Once free swimming and feeding, larvae were raised at $18^{\circ} \mathrm{C}$ in filtered and bubbled aquaria using deionized water supplemented with $0.48 \mathrm{gm} / 1$ mixed salts for tropical fish (Aquarium Systems, Mentor, $\mathrm{OH}$ ). Operated animals generally were raised in large plastic containers (Nalgene, Rochester, NY) in an $18^{\circ} \mathrm{C}$ incubator and had their water changed twice weekly. Xenopus laevis tadpoles were obtained commercially (Xenopus I, Dexter, MI) and used at stages 55-60 (Nieuwkoop and Faber, 1967). They were maintained in plastic containers, as above. All Rana tadpoles were fed boiled romaine lettuce supplemented occasionally with rat chow pellets, and all Xenopus tadpoles were fed commercial dry food powder (Nasco, Fort Atkinson, WI). Animal procedures were approved by the Yale University Animal Care and Use Committee.

\section{Three-eyed tadpole surgery}

As a sensitive measure of NMDA receptor-dependent synaptic competition, we have used the striped tecta of three-eyed tadpoles where desegregation is reversibly and consistently induced by application of the NMDA receptor antagonist AP-5 (Cline et al., 1987). Although there is controversy in mammalian systems concerning the interpretation of experiments using NMDA receptor blockade, in tadpole tecta considerable data indicate that AP-5 reversibly causes desegregation only because it blocks NMDA receptor currents and not because retinotectal synaptic activity is depressed in the presence of AP-5. The desegregation produced by AP-5 is not accompanied by the enlargement of individual RGC axon terminal arbors characteristic of tecta where TTX is used to suppress retinotectal activity (Reh and Constantine-Paton, 1985; Cline et al., 1987). Whole-cell recordings of the glutamatergic EPSCs in tadpole tecta demonstrate that NMDA receptors carry only a small component of the total excitatory current (Hickmott and Constantine-Paton, 1993), and chronic AP-5 treatment does not disrupt transmission of visual input through the tectum assayed while the blockade is in place (Scherer and Udin, 1991; Udin et al., 1992). Three-eyed Rana pipiens tadpoles were produced by transplantation of an eye primordium from a tail bud stage donor embryo to the forebrain of a second embryo and raised to late stages before metamorphosis as previously described (Law and Constantine-Paton, 1981).

\section{Local application of an $N O$ donor to Xenopus laevis $R G C$ growth cones}

Retinal explant cultures from late-stage Xenopus were prepared as described previously (Rentería and Constantine-Paton, 1996). Time-lapse microscopy of local applications of the NO donor $S$-nitrosocysteine (SNOC) to growth cones in these cultures was performed on an inverted microscope (Nikon, Tokyo, Japan) using $20 \times$ phase-contrast optics. Images were acquired using NIH Image software (version 1.60; modified by Shuh-Yow Lin of our laboratory) to control microscope shutters (Vincent Associates, Rochester, NY) and a CCD camera system (Cohu, San Diego, CA). Using custom time-lapse macros, we saved images digitally at an interval of 1 min for later analysis in NIH Image.

Pipettes were pulled on a horizontal puller (Flaming Brown P-87) to a tip diameter of $\sim 2 \mu \mathrm{m}$. Filling solutions were centrif uged in a microfuge (VWR, Piscataway, NJ) for $5 \mathrm{~min}$ before use. Filled pipettes were mounted onto the front end of a picospritzer (General Valve, Fairfield, $\mathrm{NJ}$ ) attached to a micromanipulator (Narashige, Tokyo, Japan) on the microscope. SNOC was prepared as described previously (Rentería and Constantine-Paton, 1996). In initial experiments, $100 \mathrm{~mm}$ SNOC stock solution was included in the pipette as a source of NO, and the pipette was positioned near growth cones without ejection (that is, no positive pressure was applied). We reasoned that this setup could act as a local source of NO from the pipette tip. In other experiments, local applications of 50 and $100 \mu \mathrm{M}$ SNOC were produced using $20 \mathrm{msec}$ pulses at 1 $\mathrm{Hz}$ from a stimulator to activate the picospritzer at a pressure of $3 \mathrm{psi}$ (Lohof et al., 1992). Pipettes were positioned 5-20 $\mu \mathrm{m}$ from growth cones; the distance varied during the application because only growth cones that were actively extending were selected for treatment. For these latter experiments, control solutions in the pipettes consisted of either saline alone or $0.5 \mathrm{mg} / \mathrm{ml}$ FITC-dextran ( $\sim 3000$ molecular weight; Molecular Probes, Eugene, OR) in saline, to monitor release with fluorescence optics. Ejection of solution was confirmed from all pipettes before application. Growth cones were affected at larger distances from the pipette (up to $200 \mu \mathrm{m}$ within the video frame) with the highconcentration treatment method than with the pressure applications of solutions of lower concentration.

To examine the effect of $\mathrm{NO}$ on tectal neuron processes, tectal cell cultures were prepared from Xenopus tadpoles as described previously (Lin and Constantine-Paton, 1998). Briefly, dissected optic tecta were enzymatically treated with trypsin, mechanically disrupted by trituration, and plated, with the same medium as used in the retinal explant cultures, onto glass coverslips previously coated with $100 \mu \mathrm{g} / \mathrm{ml}$ poly-L-lysine. Imaging procedures have been described previously (Rentería and Constantine-Paton, 1996).

\section{Electrophysiology}

Electrophysiology using Rana pipiens tectal slices was performed as described previously (Hickmott and Constantine-Paton, 1993). Briefly, slices were prepared in the bathing buffer consisting of (in mM): 112 $\mathrm{NaCl}, 2 \mathrm{KCl}, 17 \mathrm{NaHCO}_{3}, 3 \mathrm{MgCl}_{2}, 3 \mathrm{CaCl}_{2}$, and 12.2 dextrose, $\mathrm{pH}$ 7.3; slices were secured to the recording chamber by a thrombin clot (Blanton et al., 1989). The bathing solution was maintained near $18^{\circ} \mathrm{C}$ and continuously bubbled with $95 \% \mathrm{O}_{2}-5 \% \mathrm{CO}_{2}$, and slices were allowed to equilibrate for at least $1 \mathrm{hr}$ before recordings were begun. Pulled borosilicate glass electrodes were filled with a solution containing either (in mM): $100 \mathrm{CsMeSO}_{4}, 10$ EGTA, $20 \mathrm{HEPES}, 3 \mathrm{MgCl}_{2}, 1 \mathrm{NaCl}$, and 2 ATP-Na, pH 7.3; or $100 \mathrm{CsOH}, 100$ gluconic acid, 10 EGTA, 20 HEPES, $5 \mathrm{MgCl}_{2}, 2$ ATP-Na, and 3 GTP-Na, pH 7.3. Currents were recorded from layer 6 and layer 8 neurons using the blind, whole-cell voltage-clamp method of Blanton et al. (1989), using an Axopatch 1D amplifier (Axon Instruments, Foster City, CA) interfaced (CED 1401 Plus; Cambridge Electronics Design, Cambridge, England) to a Pentium-based computer.

Recordings were made at -70 and $-100 \mathrm{mV}$ holding potentials. Spontaneous postsynaptic current (PSC) event frequencies before and after addition of drugs were determined using semiautomatic event detection software (Ankri et al., 1994). Software-selectable criteria (such as slope, window width, and minimum number of points past threshold) were selected empirically to minimize detection of presumed false events within the noise of the traces and to detect events of at least approximately two times baseline in amplitude. For recordings at $-70 \mathrm{mV}$, these criteria should have excluded miniature and inhibitory PSCs. Analysis of recordings at $-100 \mathrm{mV}$ should have included inhibitory PSCs and possibly some miniature PSCs with the excitatory PSCs. Nevertheless, effects of NO donors were not notably different at the different potentials.

\section{NOS localization}

Immunohistochemistry. For all histological procedures, Rana pipiens tadpoles were anesthetized in $0.1 \%$ MS-222, and dissected brains were immersed in fixative containing $4 \%$ paraformaldehyde (Electron Microscopy Sciences, Fort Washington, PA) in $0.1 \mathrm{M}$ phosphate buffer, $\mathrm{pH} 7.2$, with $4 \%$ sucrose for $2 \mathrm{hr}$ at $4^{\circ} \mathrm{C}$. The brains were then soaked in PBS (in mM: $140 \mathrm{NaCl}, 2.7 \mathrm{KCl}, 10 \mathrm{Na}_{2} \mathrm{HPO}_{4}$, and $1.8 \mathrm{KH}_{2} \mathrm{PO}_{4}, \mathrm{pH} 7.2$ ) overnight at $4^{\circ} \mathrm{C}$ and cryoprotected by incubation in PBS containing $30 \%$ sucrose at room temperature. Fixed brains were mounted in embedding medium (Tissue-Tek; Miles, Elkhart, IN), and $20 \mu \mathrm{m}$ sections were cut on a cryostat, collected onto gelatin-coated slides, and stored at $-80^{\circ} \mathrm{C}$. After rehydration in PBS and incubation of sections in 5\% BSA, sections were incubated overnight at $4^{\circ} \mathrm{C}$ in primary antibody (polyclonal "bNOS"; Transduction Laboratories, Lexington, KY) diluted 1:200 in $2.5 \%$ BSA in PBS. Rhodamine- or FITC-conjugated secondary antibody 
(Jackson ImmunoResearch, West Grove, PA) was applied for $2 \mathrm{hr}$ at $37^{\circ} \mathrm{C}$. Slides were viewed on a fluorescence microscope (Nikon), and images were acquired using our imaging system.

NADPH-diaphorase histochemistry. For NADPH-diaphorase staining, tissue was prepared as described above, except that, in some cases, 80- to 200- $\mu$ m-thick free-floating sections were made by mounting fixed tissue in $3.5 \%$ low-gelling temperature agarose (type VII) with $8 \%$ sucrose and cutting it in PBS on a vibratome. For the reaction, thawed and rehydrated sections or floating sections were placed in Tris buffer $(50 \mathrm{~mm}), \mathrm{pH} 8.0$, with $0.3 \%$ Triton $\mathrm{X}-100$ for $10 \mathrm{~min}$ to $3 \mathrm{hr}$ at room temperature (Bruning et al., 1995). Reactions were performed by incubating sections in Tris buffer including $1.2 \mathrm{~mm}$ NADPH and $3.1 \mathrm{~mm}$ nitro blue tetrazolium for $1-3 \mathrm{hr}$ at $37^{\circ} \mathrm{C}$ and were stopped by two $10 \mathrm{~min}$ rinses with Tris buffer (Crowe et al., 1995; Bruning and Mayer, 1996). After dehydration and clearing, slides were permanently mounted and coverslipped (Krystalon; Harleco, Gibbstown, NJ).

\section{Elvax preparation with the NOS inhibitor $L-\mathrm{N}^{G}$-nitroarginine methyl ester}

Elvax (DuPont NEN, Willmington, DE) was prepared by the method of Silberstein and Daniel (1982) with modifications. Elvax polymer (200 $\mathrm{mg}$ ) was dissolved in $2 \mathrm{ml}$ of methylene chloride, and a $2 \mathrm{M}$ solution of the $\mathrm{D}$ - or L- form of $N^{\mathrm{G}}$-nitroarginine methyl ester (NAME) (Alexis Biochemicals, San Diego, CA) was prepared in water with warming. To the $2 \mathrm{ml}$ of dissolved Elvax, $200 \mu \mathrm{l}$ of the drug stock was added. In some cases, $20 \mu \mathrm{l}$ of $2 \%$ Fast Green dye in DMSO was also added. This mixture was vortexed for $\sim 30 \mathrm{sec}$ to produce a colloidal suspension of drug in the Elvax and placed at $-80^{\circ} \mathrm{C}$. After freezing overnight, the Elvax was dried at $-20^{\circ} \mathrm{C}$ for 1 week and then lyophilized overnight. This procedure produces a soft plastic plug that contains small pores containing drug. Plugs were mounted and frozen in embedding medium, and 60 $\mu \mathrm{m}$ slices were cut on a cryostat and stored at $-80^{\circ} \mathrm{C}$.

L-NAME was chosen because it is highly soluble in water and effectively inhibits NOS. Although systemic application in the rat is ineffective at inhibiting brain NOS because of the inability of the drug to cross the blood-brain barrier, intraventricular L-NAME application prevents NO generation in intact rat brain (Burlet and Cespuglio, 1997). Our treatment regimen delivers drug directly to the brain tissue, bypassing the blood-brain barrier, and has been successfully used to deliver the NMDA receptor antagonist AP-5 to doubly innervated tadpole tecta, which causes stripe desegregation (Cline et al., 1987).

\section{Elvax implantation}

In anesthetized, late stage [stages XIV to XVI (Taylor and Kollros, 1946)] normal and three-eyed Rana pipiens tadpoles, the skin and skull overlying the midbrain were cut and retracted. The dural membrane over the exposed surface of the tecta was opened, and a single slice of Elvax, cut to size and briefly rinsed in amphibian saline (in mM: $100 \mathrm{NaCl}, 2$ $\mathrm{KCl}, 2.5 \mathrm{CaCl}_{2}, 3 \mathrm{MgCl}_{2}, 2.8$ glucose, and 5.25 HEPES, pH 7.4), was placed over the tectal lobes. Saline was used for irrigation during this procedure. After closure of the skull and skin, histoacryl glue (Vetbond; $3 \mathrm{M}$, St. Paul, MN) was applied to the skin cut, and the animals were placed in a recovery chamber containing tadpole-rearing water supplemented with antibiotics [10 $\mu \mathrm{g} / \mathrm{ml}$ gentamicin sulfate (Life Technologies, Grand Island, NY), $50 \mathrm{U} / \mathrm{ml}$ penicillin, and $10 \mu \mathrm{g} / \mathrm{ml}$ streptomycin]. The recovery dish was bubbled with $95 \% \mathrm{O}_{2}-5 \% \mathrm{CO}_{2}$ for 1 to several hours before the animals were returned to the incubator. Elvax plastic releases substances to the underlying tissue slowly over time for over 2 months after an initial large release (Cline and Constantine-Paton, 1989). Survival after this procedure approached $100 \%$. The Elvax directly contacts the dorsal one-third to one-half of the tectal lobes with this method, and effective Elvax placement was confirmed at death.

\section{NOS activity assays of normal and L-NAME-treated Rana pipiens optic tecta}

NOS activity was monitored in tectal homogenates after 2 , 4 , or 6 weeks of treatment by the conversion of ${ }^{3} \mathrm{H}$-arginine to ${ }^{3} \mathrm{H}$-citrulline using the procedure of Sessa et al. (1992) with slight modifications. Briefly, tadpoles were anesthetized in $0.1 \%$ MS-222, and their midbrains were quickly dissected into oxygenated saline solution. Optic tecta were dissected free from ventral midbrain areas, which contain additional NOSpositive nuclei (our unpublished observations). However, entire tectal lobes were used for the assay. Therefore, not all of the assayed tissue was in direct contact with the dorsally implanted Elvax and so included areas that were exposed to lower levels of L- and D-NAME. These dissected tectal lobes were homogenized on ice in buffer consisting of $50 \mathrm{~mm}$ Tris-HCl, pH 7.4, 1\% NP-40 (Boehringer Mannheim, Indianapolis, IN), $0.1 \mathrm{~mm}$ EDTA, $0.1 \mathrm{~mm}$ EGTA, and protease inhibitors (Complete; Boehringer Mannheim). Homogenates were rocked for $30 \mathrm{~min}$ at $4^{\circ} \mathrm{C}$ and then spun in a microfuge at $14,000 \times g$ at $4^{\circ} \mathrm{C}$ to yield a supernatant with a final protein concentration usually of $1-2 \mathrm{mg} / \mathrm{ml}$, depending on the stage of the animals. Sample groups consisted of three pairs of tectal lobes from three animals homogenized in $150 \mu \mathrm{l}$ of buffer, yielding material for duplicate NOS assay samples and for protein determination. Protein concentration of each homogenate was measured (DC Protein Assay; Bio-Rad, Hercules, CA) for two dilutions of the homogenate supernatant, each in duplicate or triplicate.

For reactions, NOS cofactors were added; the final concentrations of these were $100 \mathrm{~nm}$ calmodulin, $1 \mathrm{~mm}$ NADPH, $30 \mu \mathrm{M}$ tetrahydrobiopterin (Schricks Laboratory, Jona, Switzerland), $2.5 \mathrm{mM} \mathrm{CaCl}_{2}$, and 10 $\mu \mathrm{M}$ L-arginine. Duplicate reactions for each sample group were performed in a final volume of $100 \mu \mathrm{l}$, which included $50 \mu \mathrm{l}$ tectal protein (or homogenization buffer alone in the case of blanks), cofactors in buffer as above, and $0.2 \mu \mathrm{Ci}$ of $\mathrm{L}-\left[2,3,4,5-{ }^{3} \mathrm{H}\right]$-arginine monohydrochloride (Amersham, Arlington Heights, IL). Untreated tectal tissue from approximately stage-matched animals was run in parallel with each assay of treated tissue to ensure that NOS activity could indeed be detected. Reactions were incubated in a $37^{\circ} \mathrm{C}$ water bath and stopped after $40 \mathrm{~min}$ by the addition of $1 \mathrm{ml}$ of stop buffer consisting of (in mM): 20 HEPES, 2 EDTA, and 2 EGTA, pH 5.5. These samples were passed over disposable columns containing $1 \mathrm{ml}$ of Dowex-50W X8-200 resin, which had been converted previously to the $\mathrm{Na}^{+}$form (by incubation in $1 \mathrm{M} \mathrm{NaOH}$, followed by extensive washes in water) and equilibrated in stop buffer. In this form, the resin binds charged arginine while allowing uncharged citrulline to flow through. Columns were eluted with $1 \mathrm{ml}$ of water. Effluent was collected directly into $20 \mathrm{ml}$ glass vials containing $5 \mathrm{ml}$ of scintillation fluid (Opti-Fluor; Packard, Meriden, CT), and vials were assayed on a $\beta$ counter (Beckman Instruments, Fullerton, CA). The average count from column effluents of triplicate blanks was subtracted from the values for column effluents of samples containing protein for each NOS activity assay. Also, for each experiment, triplicate blanks were counted without passage over columns to determine the average total labeled arginine added to each sample. All experimental values were normalized for these total counts and for total protein to allow comparisons among the different experiments.

To minimize the risk of inhibition of NOS during dissection and homogenization, the Elvax containing drug was removed before tectal dissection. The tissue was dissected and rinsed in a large volume of saline solution alone, and the volume of homogenization buffer used was several times the volume of the tissue.

\section{Visualization of the optic projection from a single eye}

After 4 weeks of treatment, three-eyed tadpoles were anesthetized as above, a small incision was made behind the supernumerary eye, and the optic nerve from that eye was severed. Pieces of gel foam that had been soaked in a saturated solution of horse radish peroxidase (HRP) type VI were implanted against the optic nerve stump. After $2 \mathrm{~d}$ survival to label the optic projection, anesthetized tadpoles were perfused with saline solution, followed by a freshly made and filtered diaminobenzidine (DAB) $\mathrm{HCl}$ solution consisting of $1.4 \mathrm{~mm}$ DAB in a Tris- $\mathrm{NaCl}$ solution, which contained $50 \mathrm{~mm}$ Tris- $\mathrm{HCl}, \mathrm{pH} \mathrm{7.4}$, and $100 \mathrm{~mm} \mathrm{NaCl}$. The brain of each animal was dissected into ice-cold DAB solution, and the pia was carefully removed. For the reaction, the brain was transferred to ice-cold DAB solution containing $0.006 \% \mathrm{H}_{2} \mathrm{O}_{2}$ and $1.5 \%$ DMSO. After $15-45$ min, when reaction product was clearly visible, the brain was washed twice in Tris- $\mathrm{NaCl}$ to stop the reaction.

For flat-mounting, the tectal lobes were dissected, and cuts were made at each pole. Cut lobes were placed on glass slides, and, using insect pins in silicon grease as spacers, a chamber was created by pressing a coverslip onto the spacers, flattening the tecta. These chambers were perfused with fixative and stored at $4^{\circ} \mathrm{C}$ for 1 week. Fixed tectal lobes were dehydrated by incubations in increasing percentages of ethanol, cleared, and permanently mounted and coverslipped for microscopic observation and photography (Nikon). Although a few treated animals appeared to have a lower innervation density beneath the Elvax, this was seen in both D- and L-NAME-treated animals and did not alter the formation of a striped pattern, which was visible in all of these animals.

The whole-brain DAB labeling procedure reveals reliably only the RGC axon termination pattern in the most superficial layers of the tectal 
neuropil. To examine segregation of deeper layers receiving optic input, anesthetized tadpoles were perfused with saline solution, followed by fixative. The brains of these HRP-labeled animals were dissected as above, fixed for $2 \mathrm{hr}$, incubated in PBS overnight at $4^{\circ} \mathrm{C}$, and embedded in $3.5 \%$ low-gelling temperature agarose (type VII) with $8 \%$ sucrose in PBS. This tissue was sectioned coronally at $80 \mu \mathrm{m}$ using a vibratome, washed in Tris- $\mathrm{NaCl}$ solution, and incubated in DAB solution for $10 \mathrm{~min}$. The reaction was performed and stopped as above. Slices were washed in PBS and mounted onto gelatin-coated slides. These were dried and rehydrated in PBS, followed by dehydration, clearing, and coverslipping, as above.

\section{RESULTS}

Previous experiments showed that RGC growth cones collapse when whole retinal explants from Xenopus are exposed to NO generated by bath-applied NO donors (Rentería and Constantine-Paton, 1996). The in vitro experiments reported here, using the NO donor SNOC (which produced robust collapsing responses in our earlier work), addressed two additional issues. First, we determined whether bath application of SNOC to Xenopus tectal neurons in vitro would also cause motility inhibition and collapse of tectal cell neurites. The experiments showed that tectal cell neurite motility was inhibited by SNOC application (100 $\mu \mathrm{M}$ SNOC: $n=3$ of 3 ) but not by exposure to donor solution, which had exhausted its NO (100 $\mu \mathrm{M}$ exhausted SNOC: $n=0$ of 3$)$, suggesting that the motility of both RGC axons and tectal neurites are similarly affected by SNOC exposure.

In our previous study, NO had access to the retinal circuitry and the RGC cell bodies in the retinal explant because the NO donors were bath-applied. Data from other systems has shown that NO can increase synaptic activity (Cudeiro et al., 1996), an effect which might complicate interpretation of experiments using bath-applied NO donors if NO altered activity in the retinal explant, because neuronal activity can alter axon growth (Cohan and Kater, 1986). Furthermore, a control for activity changes induced by NO was felt to be important because data collected from tectal slices indicated variable effects of bath-applied NO donors on synaptic events. Initial whole-cell voltage-clamp data from a Rana pipiens tectal slice preparation suggested that NO could alter retinotectal synaptic responses evoked by optic tract stimulation because increased amplitudes of excitatory PSCs in the presence of either NO donors ( $n=2$ cells) or the membranepermeable cGMP analog 8-bromoguanosine-cGMP $(n=1$ cell) were observed (Rioult-Pedotti et al., 1995). An increased frequency of spontaneous PSCs was also observed in the preliminary study. Nonetheless, an analysis of a much larger set of recorded epochs ( $n=58$ epochs of $70 \mathrm{sec}$ each) indicated that any effect of NO on spontaneous PSCs was highly variable, and these experiments were not pursued further.

\section{RGC axonal growth cones collapse after local application of the NO donor SNOC}

Therefore, a second series of in vitro experiments was undertaken to control for possible effects of NO donor bath application on retinal activity by applying SNOC directly to RGC growth cones. Initially, pipettes containing $100 \mathrm{~mm}$ SNOC, an NO donor, were positioned for a period of 10-20 min near growth cones actively extending from a Xenopus retinal explant. Both the motility and structure of growth cones were affected, and the effects appeared similar to those seen in our previous study (Rentería and Constantine-Paton, 1996). Fourteen growth cones were examined in four separate experiments. Of these, only one appeared unaffected. The motility of the 13 others was significantly inhibited, and 10 of these collapsed. Four of these growth cones recovered
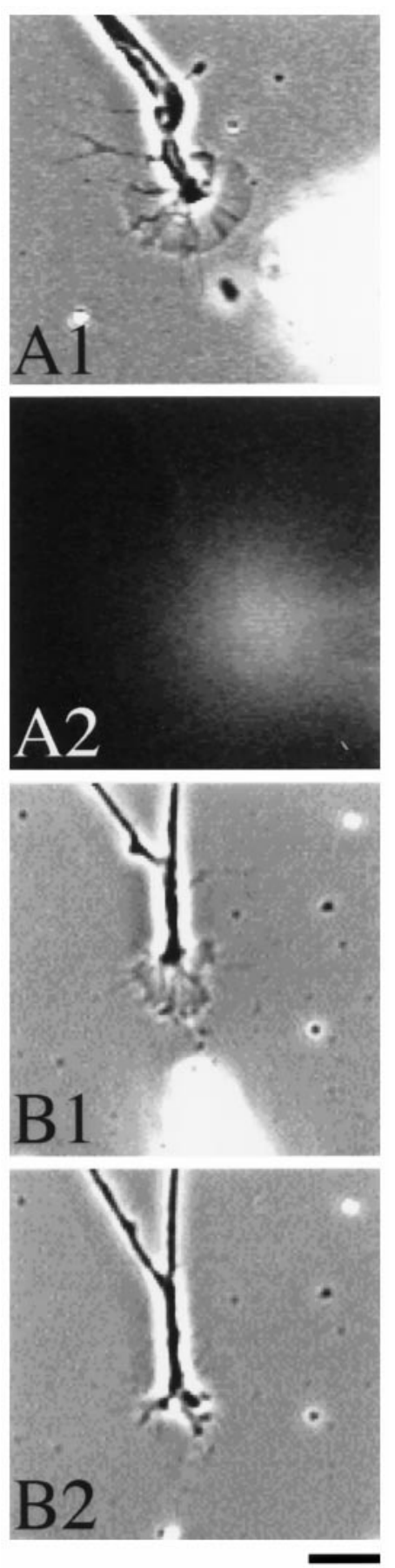

Figure 1. Local application of the NO donor SNOC causes RGC axonal growth cone collapse. A1, A phase image of a pipette filled with FITCdextran control solution positioned near an RGC axonal growth cone is shown. $A 2$, This is the same field as $A 1$ but was imaged using fluorescence optics. Pulses of positive pressure applied to the pipette release small amounts of the FITC-dextran solution. B1, Pipettes were filled with solutions containing the NO donor SNOC and positioned near actively extending growth cones. Positive pressure to the pipette caused release of NO donor solution onto the growth cone. B2, This is the same field as B1 but 5 min after the onset of SNOC application. Puffs of the NO donor solution caused motility inhibition and collapse of the lamellipodium in this growth cone and most of the others examined. Scale bar, $10 \mu \mathrm{m}$. 
lamellipodial structures and began to advance. In two experiments, a repeat exposure of these recovered growth cones to the SNOC-containing pipette caused similar effects on motility and structure.

To better control the applied NO donor concentration, we next locally applied 50 or $100 \mu \mathrm{M}$ SNOC, diluted in the saline used for imaging, using pulses of positive pressure applied to the pipette. Control solutions of either saline or FITC-dextran had no effect on motility or growth cone structure $(n=4)$. An example of an application of FITC-dextran from a pipette to a growth cone is shown in the phase image of Figure $1 A 1$, and the solution can be seen to extend over the growth cone area in the fluorescence image of the same field at approximately the same time in Figure $1 A 2$. In contrast to control solutions, puffs of SNOC applied very locally to growth cones using this technique caused marked alterations in motility and structure (Fig 1B1,B2). Some response heterogeneity among different growth cones was noted. Of the five growth cones to which $100 \mu \mathrm{M}$ SNOC was applied, the motility of three decreased, leading to collapse, one showed similar effects on motility but did not collapse completely, and one was unaffected. The affected growth cone that did not collapse fully recovered and began to extend again.

The cause of these differences in responsiveness is unclear. A major effect of NO in cells is to cause cGMP production, and recent reports suggest that variability of turning responses in spinal cord growth cones reflects differences in internal cGMP or cAMP concentration (Song et al., 1998). However, changes in cGMP are unlikely to be responsible for the varied responses of RGC growth cones because we have shown previously that the motility effects of $\mathrm{NO}$ on these growth cones are not mimicked by membrane-permeable analogs of cGMP (Rentería and ConstantinePaton, 1996). Alternatively, the different experiments may have simply differed in amounts of NO generated by the SNOC released from the pipette into the surrounding medium.

\section{Many neurons in tectal visual layers contain NOS}

All of the tissue culture experiments were performed using $X e$ nopus laevis tadpoles because of the need for larger numbers of tadpoles and their greater availability relative to Rana. Xenopus tadpoles have been shown to use NMDA receptor-dependent mechanisms during mapping (Udin and Fawcett, 1988) and to produce striped segregation patterns in tectal lobes innervated by separate retinal regions (Fawcett and Willshaw, 1982; Ide et al., 1983). NOS is localized to a dispersed population of tectal neurons in the Xenopus tectum (Bruning and Mayer, 1996). However, Rana pipiens tadpoles are advantageous for in vivo analyses of the effects of NOS inhibition on retinal afferent segregation in the tectum because they have larger tectal lobes than Xenopus tadpoles, enabling the biochemical analysis of NOS activity, and because double innervation of tectal lobes followed by analysis of retinal afferent patterns is more readily obtained in Rana. Therefore, we first asked whether the distribution of NOS within the Rana pipiens optic tectum is the same as that seen in Xenopus.

The amphibian tectum can be divided into nine distinguishable alternating plexiform and cell layers (Székely and Lázár, 1976). Layer 9 consists of a dense neuropil containing the retinal axons, which form synaptic contacts onto dendrites arising from neurons in layers 4,6 , and 8 . These postsynaptic neurons extend efferent axons that form layer 7. NADPH-diaphorase activity in fixed neural tissue is known to be caused by NOS activity (Hope et al., 1991). As shown in Figure 2A, NADPH-diaphorase staining of Rana tadpole tecta revealed NOS activity in neuronal cell bodies

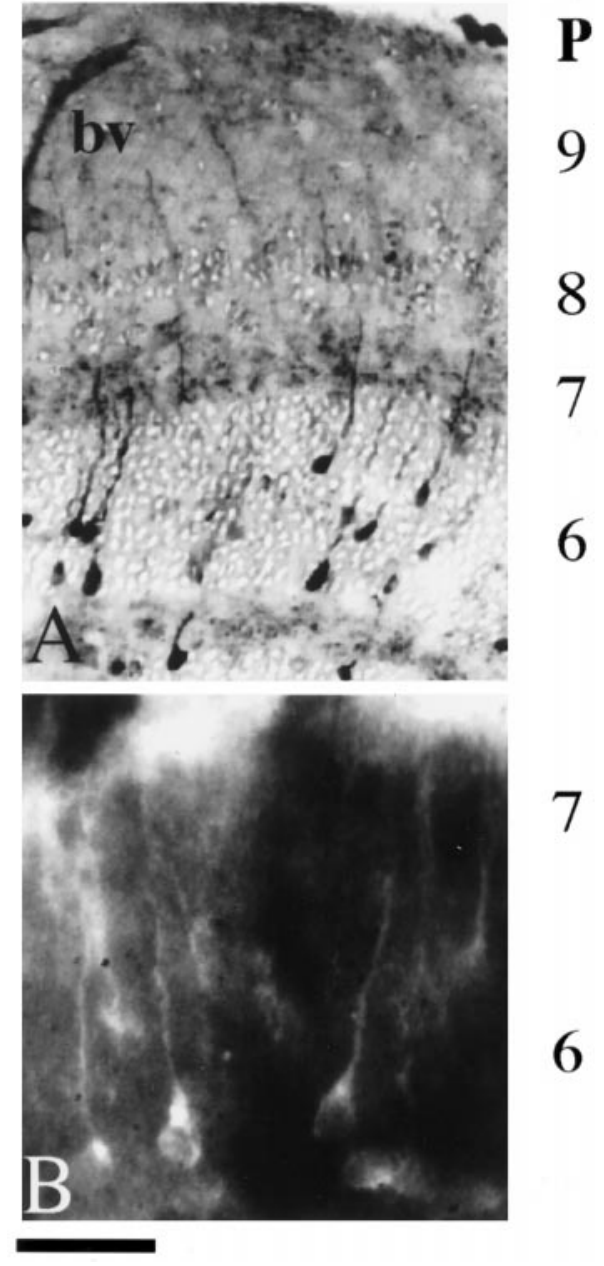

Figure 2. Both NADPH-diaphorase and immunohistochemistry reveal NOS in neurons in tadpole optic tectum. Dorsal is $u p$, and lateral is to the right. $A$, Several NADPH-diaphorase-positive neurons in the densely packed layer 6 , the main retinorecipient cell layer, can be seen sending apical dendrites dorsally that penetrate the layer 9 neuropil. In addition, three neurons in layer 4 and a single neuron in layer 8 are labeled. Blood vessels $(b v)$ are also labeled in this tissue. $P$ indicates the pial membrane layer. $B$, A coronal section from another tectum was immunostained with a commercial polyclonal type I NOS antibody. Layers 6 and 7 are shown. Several neurons with a morphology similar to those in NADPHdiaphorase-stained tissue can be seen. Scale bar: A, $80 \mu \mathrm{m}$; B, $50 \mu \mathrm{m}$.

and their apical processes extending into the layer 9 neuropil, as well as in axonal processes in layer 7 . These axons arise directly from the apical dendrite as it passes through layer 7 and were uniformly stained.

Many cells in layer 6 of the Rana tectum were stained, as were cells in layers 8 and 4 . Labeled cells represented from 1 to $5 \%$ of the layer 6 neurons, similar to the levels seen in the mammalian cortex (Sandell, 1986; Kuchiiwa et al., 1994). Despite the age disparity between rostral and caudal tectal neurons, no reliable rostrocaudal gradient of expression was seen. Expression was also seen in far caudal tectal areas of young tadpoles in which retinal innervation is lacking (Reh and Constantine-Paton, 1983). Brain blood vessels, which likely contain endothelially localized NOS functioning for vessel dilation, were also stained.

A notable aspect of the neuropil staining was the generally light labeling throughout (Fig. $2 A$ ). Using DAB visualization of HRPlabeled retinal axons, followed by NADPH-diaphorase histo- 


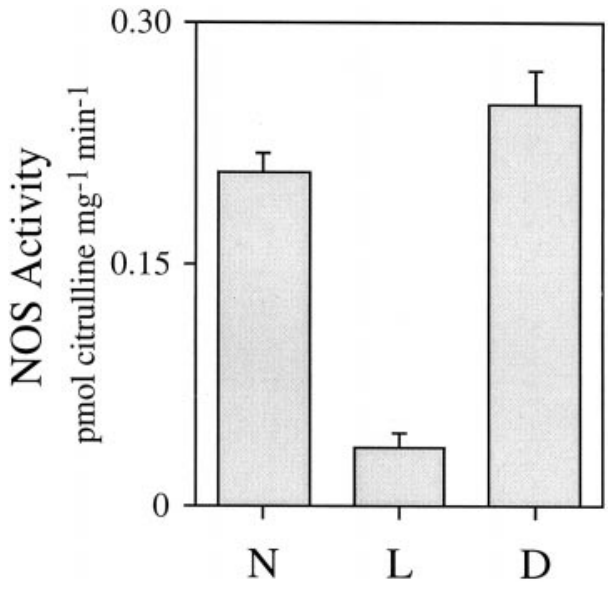

Figure 3. Chronic treatment of normal, developing Rana pipiens tadpole optic tecta with L-NAME but not D-NAME in Elvax inhibits tectal NOS activity. L-NAME is a NOS inhibitor, and D-NAME is the inactive isomer used as a control. The normal groups $(N)$ were untreated, the L-NAME groups $(L)$ were assayed at 2, 4, and 6 weeks of treatment, and the D-NAME groups $(D)$ were assayed at 2 and 4 weeks of treatment. Degree of blockade did not correlate with treatment time. Mean \pm SEM.

chemistry of the same tissue, we found that RGC axons observed at the optic chiasm and along the optic tract do not contain NOS activity. This suggests that the staining in the tectal neuropil in which retinal afferents make contacts on tectal processes was localized in fibers originating from tectal neurons and possibly from other inputs but not from RGCs.

To correlate the NADPH-diaphorase staining in our Rana tectal tissue to NOS protein, tectal sections were stained with a commercial antibody that recognizes type I NOS. In Figure $2 B$, NOS expression can be seen in several layer 6 neurons. The distribution of immunohistochemically labeled neurons was similar to that in NADPH-diaphorase stained material. The apical processes and cell bodies of these typical, pear-shaped neurons are clearly labeled. Layer 7 contains much label as well. These observations in Rana tectum are fully consistent with those obtained in Xenopus (Bruning and Mayer, 1996).

\section{Chronic treatment with Elvax containing L-NAME inhibits NOS activity in the optic tectum}

To test whether NOS activity is necessary for stripe segregation, we chronically inhibited NOS in the tecta of normal and threeeyed Rana pipiens tadpoles using implantation of L-NAMEinfiltrated Elvax. Groups of L-NAME Elvax-implanted animals were killed after 2, 4, and 6 weeks of treatment, and homogenates of the six tectal lobes from the three animals in each group were assayed for NOS activity. D-NAME Elvax-implanted animals were tested after 2 or 4 weeks of treatment. As shown in Figure 3, Elvax containing the NOS inhibitor L-NAME, but not that containing the inactive isomer D-NAME, inhibited NOS activity in tectal tissue (mean $\pm \mathrm{SEM} \mathrm{pmol} \cdot \mathrm{mg}^{-1} \cdot \mathrm{min}^{-1}$ citrulline: normal, $0.206 \pm 0.014 ; n=9$; L-NAME, $0.036 \pm 0.009 ; n=6$; D-NAME, $0.249 \pm 0.020 ; n=4)$. The mean D-NAME NOS activity level was not significantly different from the mean normal level, whereas the mean L-NAME activity level was highly significantly different from that of both normal and D-NAME controls $(p<0.001$; ANOVA with post hoc tests). The values for the L-NAME groups ranged from 30 to $6 \%$ of the mean NOS activity level of the normal groups and from 25 to $5 \%$ of the mean NOS activity level of the D-NAME groups. Blockade was seen at 2, 4, and 6 weeks of treatment ( $n=2,3$, and 1 group, respectively, for L-NAME-treated groups of animals) (Fig. 3), and the degree of blockade did not correlate with treatment time, indicating that chronic inhibition of the enzyme was achieved with these treatments.

These blockade values are likely to underestimate the degree of NOS blockade achieved directly under the Elvax implant because the one-half to two-thirds of the tectal lobes not directly under the L-NAME Elvax were included in the assay and because dissection and homogenization likely washed away some inhibitor from the small tissue volumes (see Materials and Methods). One of the seven groups of animals treated with Elvax containing the active isomer of the NOS inhibitor did not show robust inhibition of activity. The NOS activity level of this group was close to the lowest of the normal levels measured (0.135 vs 0.146 $\mathrm{pmol} \cdot \mathrm{mg}^{-1} \cdot \mathrm{min}^{-1}$ citrulline, respectively). This particular batch of Elvax was eliminated from all further analyses.

\section{Chronic NOS inhibition does not desegregate stripes in the doubly innervated tectum}

Four weeks after the implantation of Elvax infiltrated with either L- or D-NAME to three-eyed tadpoles, the projection of the supernumerary eye was labeled using anterograde HRP transport along the cut optic nerve. The projections from untreated threeeyed tadpoles were also examined. All of the animals, whether they were treated with L-NAME $(n=14)$ or D-NAME $(n=5)$, had labeled retinal afferents segregated into eye-specific stripes. In all cases, the stripes were indistinguishable from those of untreated animals ( $n=4$ for the current study). No labeled afferents appeared to be in the process of desegregation, and in no case did we observe stripe sharpening, an effect that occurs when NMDA receptor function is downregulated by chronic NMDA treatment (Cline et al., 1987; Yen et al., 1995; Hickmott and Constantine-Paton, 1997). Figure 4 shows examples of the normal stripes we observed in untreated (Fig. 4A1,A2) and L-NAME-treated (Fig. 4B1-B3,C) doubly innervated tecta. The patches of label in caudal areas (Fig. 4B3) are normal "puffs" seen in doubly innervated tecta (Constantine-Paton and FerrariEastman, 1987).

The supernumerary eye will often send axons to both tectal lobes. In these instances, dense innervation and segregation are frequently restricted to approximately complementary regions of both tectal lobes with lighter innervation and less distinct stripes localized to the edges of the striped zones in which regions of the supernumerary retina project at lower density to each of the two tectal lobes. Examples of this occurred in untreated and in both D- and L-NAME-treated tadpoles. If the degree of effect of NO on segregation were dependent on the density of the segregating afferent populations, L-NAME treatment would produce evidence of desegregation in tecta with complementary striping, particularly in boundary regions in which supernumerary eye innervation of specific tectal areas is likely to be divided between the two tectal lobes. Two examples of such complementary innervation are shown in Figure 5. Figure 5, $A 1$ and $A 2$, shows the left and right tectal lobes, respectively, from a single D-NAMEtreated animal, and Figure 5, B1 and B2, shows the same for an L-NAME-treated animal. The afferent stripes in the lobes are approximately complementary. In Figure 5A1, the caudolateral aspect is lacking innervation from the nasodorsal retina, and these axons are seen in their proper caudolateral location in the other tectal lobe, shown in Figure 5A2. Similarly, in Figure 5B1, the axons from the central retina of the supernumerary eye, which 
Figure 4. Chronic L-NAME treatment does not desegregate stripes in the doubly innervated optic tectum of threeeyed tadpoles. In $A$ and $B$, the supernumerary optic nerve was labeled with HRP, and the brain was reacted with DAB. The labeled tectal lobe was cut at the rostral and caudal poles and then was flat-mounted. Rostral is $u p$, and medial is to the right. (The black curves in some images are outside of the tissue and are the edge of an air bubble within the slide.) $A 1, A 2$, Doubly innervated tecta from two untreated tadpoles show normal eye-specific stripes. The forks, fusions, and breaks in the stripes are all normal. B1-B3, L-NAME treatment for 4 weeks does not alter stripe segregation. Three different tectal lobes from treated animals are shown; all stripes appear normal. Note that stripe sharpening, seen as very abrupt boundaries of each stripe and which occurs with chronic NMDA treatment (Cline and Constantine-Paton, 1990), is also not observed after L-NAME treatment. A good example of the puffs characteristic of caudal-most areas in many doubly innervated tecta can be seen in B3. The small black dots in $B 1$ and $B 2$ are pieces of pigmented membrane that escaped removal during dissection. $C$, A coronal section from an L-NAME-treated threeeyed tadpole optic tectum reveals that stripe segregation occurred throughout the thickness of the neuropil, indicating that segregation for all RGC types was normal under conditions of chronic NOS inhibition. Dorsal is $u p$, and lateral is to the right. Scale bar: $A, B, 500 \mu \mathrm{m} ; C$, $400 \mu \mathrm{m}$.

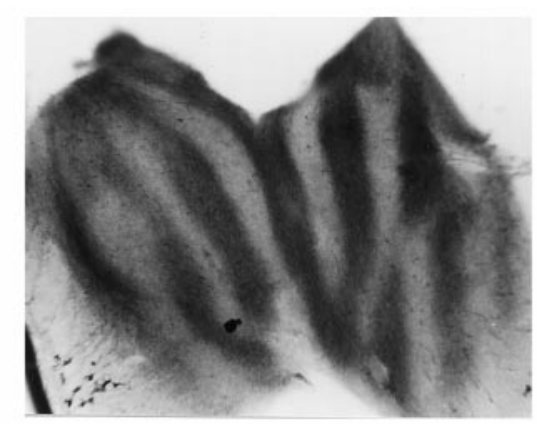

A1 Untreated
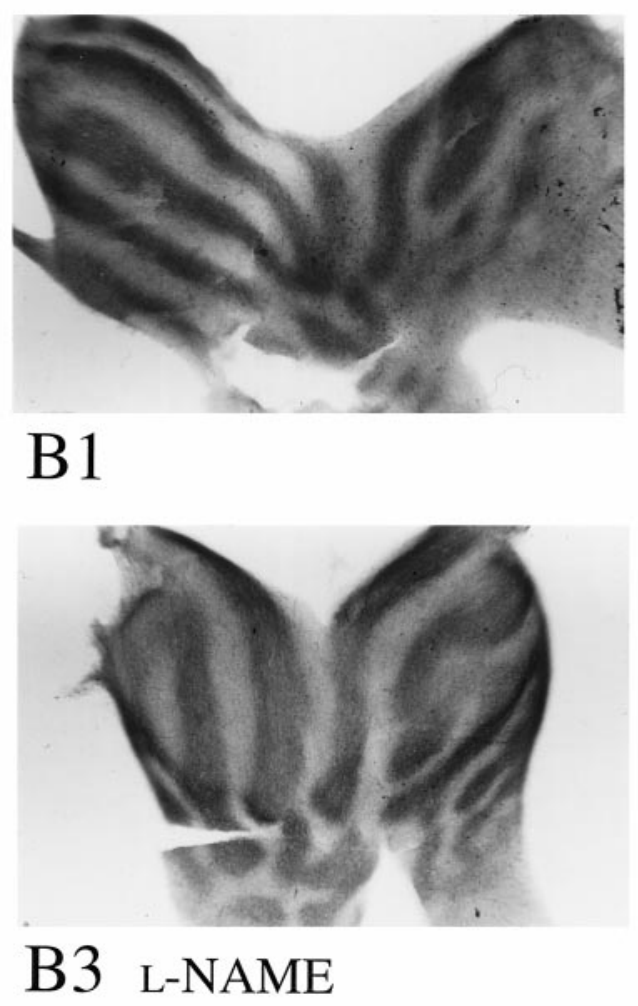

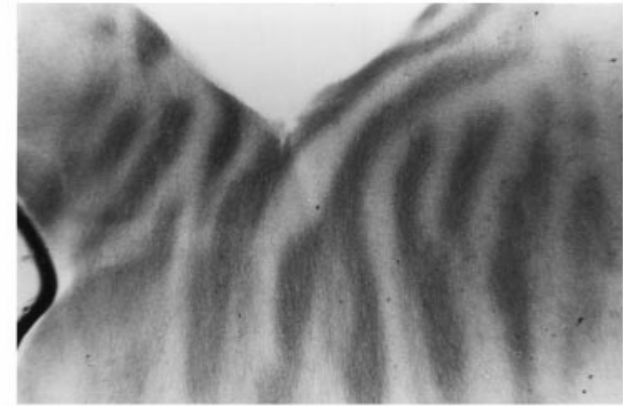

A2

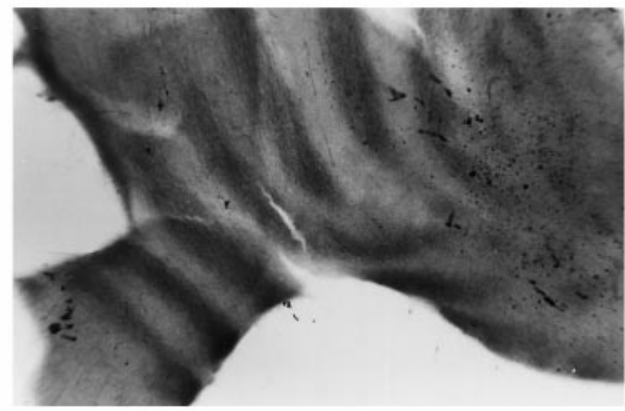

B2

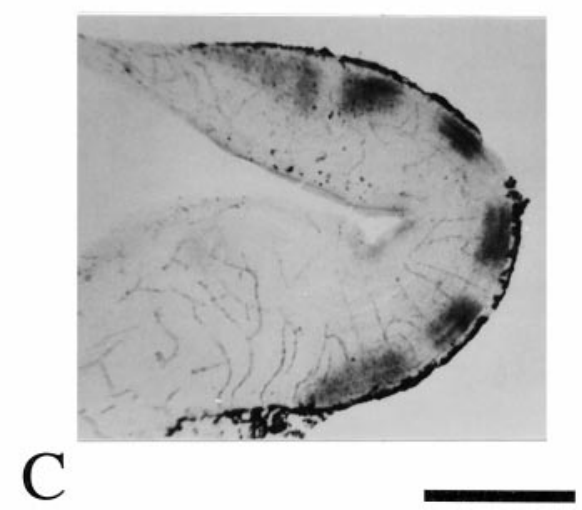

would project to the central tectum, are not represented, and these axons can be found projecting to the center of the other tectal lobe (Fig. 5B2). This indicates that the retinal arbors projecting to the two lobes obey normal topographic positioning cues, of both a chemical and an activity-dependent nature. As in animals with only one striped tectal lobe, normal segregation of afferents occurred, even in regions showing only low-density innervation by the supernumerary eye.

To ensure that NOS inhibition was not disrupting segregation of retinal inputs in deeper layers that are not clearly visible in whole-mounted tecta, L-NAME-treated $(n=5)$ and D-NAMEtreated $(n=2)$ tecta were coronally sectioned after HRP labeling of the optic nerve of the supernumerary eye, and the sections were reacted with DAB. As shown in Figure $4 C$, the retinal input was segregated throughout all the retinorecipient layers of the neuropil, as is seen in untreated doubly innervated tecta (Constantine-Paton and Law, 1978; Law and Constantine-Paton, 1981).

\section{DISCUSSION}

NO has been advanced as a retrograde signal, which could mediate developmental plasticity by initiating changes in presynaptic arbor structure after postsynaptic NMDA receptor activation. To exert such an effect, NO should be capable of affecting RGC axon motility, should be present in the postsynaptic cell population that expresses NMDA receptors, and should have a relatively consistent effect on synaptic currents. Our observations showing structural effects on retinal axons and tectal neurons after acute NO application in vitro support the hypothesis that retinotectal contacts can respond to NO if it were released locally from tectal neurons in response to synaptic activation. The identification of a subset of neurons showing NOS activity in the retinorecipient layers of the tadpole optic tectum is consistent with the hypothesis of postsynaptic release. Nevertheless, suppression of up to $95 \%$ of NOS activity by chronic treatment of optic tectum with L-NAME had no effect on the eye-specific segregation of retinal 


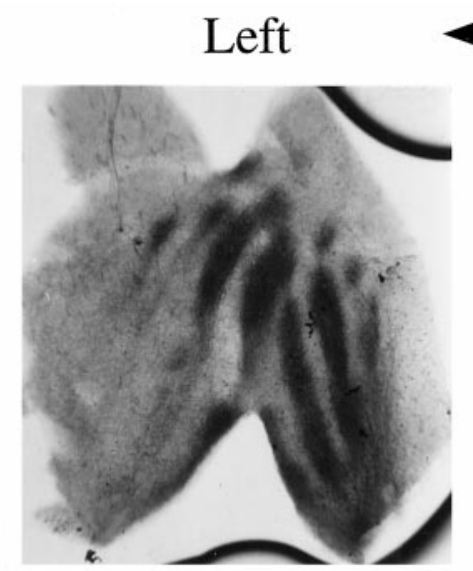

A1 D-NAME

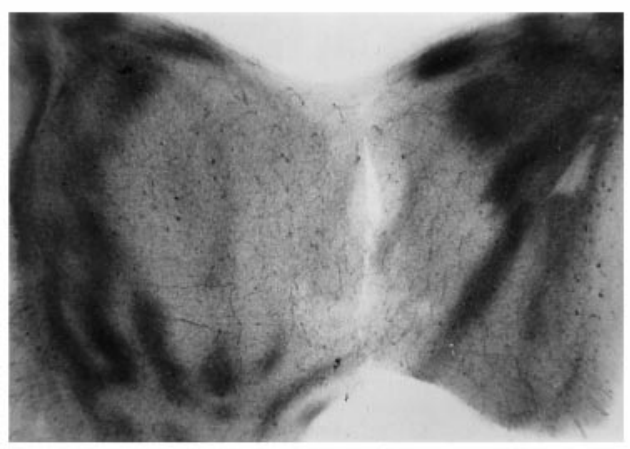

B1 L-NAME
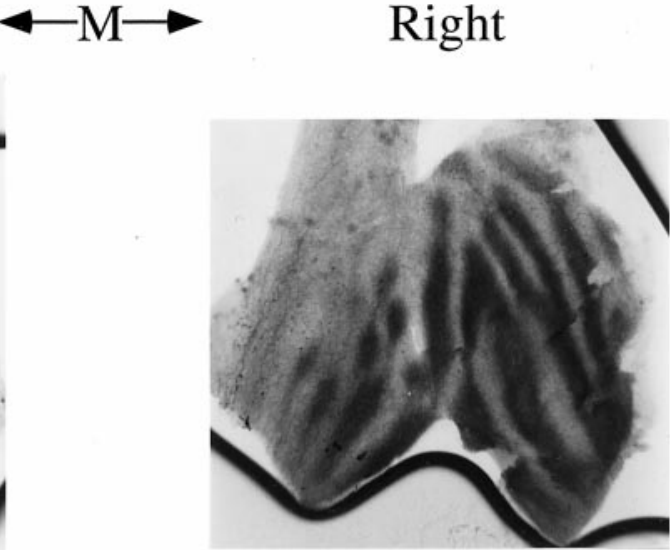

A2

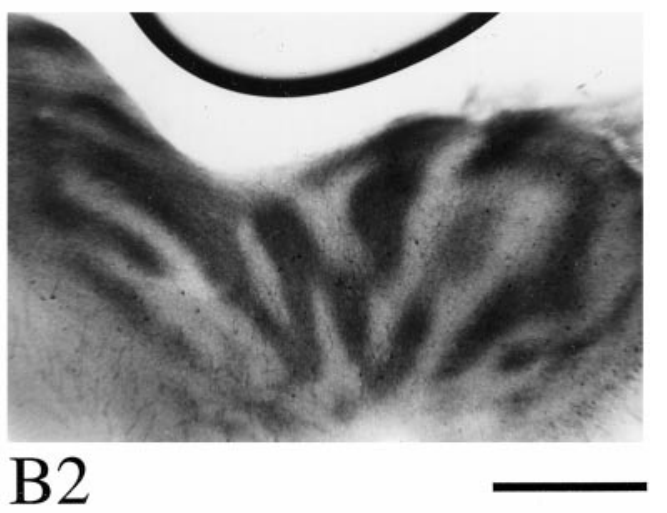

Figure 5. Normal eye-specific stripes are also preserved in tadpole tecta with chronic NOS inhibition when the supernumerary retina innervates complementary areas of the two tectal lobes. Projections were labeled as in Figure $4 A$ and $B$. Medial $(M)$ is in the middle of the figure, and lateral is in the direction of the arrows, toward the outside of the figure for each tectal lobe. In both $A$ and $B$, the stripes are complementary. In areas with double innervation, eye-specific stripes form. $A 1, A 2$, Both tectal lobes (left and right) from a single animal chronically treated with D-NAME, the inactive isomer, are shown. The supernumerary eye innervated and caused segregation in the medial region of the left tectal lobe and the lateral region of the right tectal lobe. $B 1, B 2$, Both tectal lobes (left and right) from a single animal chronically treated with L-NAME, which inhibits NOS, are shown. The supernumerary eye innervated and caused segregation along the medial and lateral border of the left tectal lobe and within the central region of the right tectal lobe. In both sets of tecta, regions of low-density supernumerary eye innervation also show evidence of segregation. Scale bar: $A, 400 \mu \mathrm{m} ; B, 500 \mu \mathrm{m}$. afferents in doubly innervated tecta. This segregation uses the same activity-dependent mechanism that refines maps (Udin and Fawcett, 1988), and both processes have been shown in earlier work to be critically dependent on NMDA receptor activation (Cline et al., 1987; Cline and Constantine-Paton, 1989). Therefore, despite the consistent morphological effects of NO donors on cultured RGC axons and tectal neurons, NO does not appear to be a critical retrograde signal during the in vivo refinement of the retinotectal map.

This failure to detect an in vivo effect of NOS blockade is similar to that previously reported using the kitten visual cortex during the period of LGN afferent segregation into ocular dominance columns within layer IV. Correlated activity from RGCs within one eye, which is poorly correlated with the activity of the other eye, is believed to guide segregation (Stryker and Strickland, 1984; Katz and Shatz, 1996; Finney and Shatz, 1998). Monocular lid suture leads to expansion of the territory of the nondeprived eye in layer IV and to its increased effectiveness at driving cortical neurons at the expense of inputs from the deprived eye (Hubel et al., 1977; Antonini and Stryker, 1996). Physiological assessment of cortical cell inputs after chronic infusion of the NMDA receptor antagonist AP-5 shows that monocular deprivation-induced plasticity of ocular dominance columns is dependent on NMDA receptor activation (Kleinschmidt et al., 1987; Bear et al., 1990). Furthermore, NMDA stimulation of cortical synaptosomes enhances glutamate and norepinephrine release by an NO-dependent mechanism (Montague et al., 1994). Nevertheless, NOS inhibition during the critical period for monocular takeover after unilateral deprivation does not block corti- cal ocular dominance plasticity (Reid et al., 1996; Ruthazer et al., 1996). It remains formally possible that NO may be redundantly used with a second system in the mammalian cortex and the frog tectum that is also downstream of NMDA receptor activation and that can compensate for the lack of NO when NOS is inhibited. However, at least in the frog, this explanation seems unlikely given the high variability of synaptic effects produced by NO donors applied to tectal slices.

A role for NO in NMDA receptor-dependent structural modification of presynaptic arbors has been suggested by work in systems that are superficially similar to the frog visual projection used here. However, these systems differ from the frog in several respects. In the chick retinotectal pathway, the ipsilateral RGC axonal projection to the optic tectum is normally eliminated during development both by RGC cell death and by removal of ipsilaterally projecting arbors from surviving neurons. NMDA receptor blockade decreases NOS activity and prevents the removal of a subset $(\sim 10 \%)$ of these ipsilateral arbors (Ernst et al., 1999); NOS inhibition has similar effects (Wu et al., 1994). This NOS-dependent withdrawal of presynaptic arbors, when considered in light of the collapsing effects of NO on RGC growth cones in vitro (Fig. 1) (Rentería and Constantine-Paton, 1996), raises the possibility that a broadly diff using but labile signal such as NO may be an effective mediator for arbor retraction but not for the continual local arbor restructuring that is fundamental to the establishment of topography, even though both processes share NMDA receptor activation as an initiating event.

For example, a significant difference between the patterns and intensity of activity that are being discriminated is likely to exist 
between the frog retinotectal map and the chick ipsilateral retinotectal projection. The ipsilateral arbors in the chick optic tectum arise from RGCs that are apparently randomly spaced in the retina (Wu et al., 1994). Consequently, unlike the activity in the contralateral arbors, which are stabilized in local tectal areas, ipsilateral RGC activity is not likely to be correlated because these RGCs are not in neighboring retinal positions. Furthermore, the ipsilateral axons are relatively low in number compared with the contralateral projection so that they are unlikely to compete effectively with the powerful contralateral input. On the other hand, during topographic mapping and the afferent segregation that occurs within such maps, the competing retinal inputs both have large numbers of afferents with relatively balanced levels of activity that is correlated among inputs arising from the same retinal areas (Constantine-Paton et al., 1990). Recent studies examining the potentiation and depression of retinotectal synapses during the initial refinement of the Xenopus retinotopic map have substantiated both the role of NMDA receptors and the importance of precise activity correlations in the competition process, demonstrating that the timing of action potential arrival from two converging RGCs is a critical parameter for the kind of synaptic change that results (Zhang et al., 1998). Presumably, the structural withdrawal of the poorly correlated and topographically inappropriate inputs relies on similarly fine temporal discriminations. This process is one in which removal of branches in one region of the arbor is balanced by addition of a new branch on the same arbor in a slightly different location (O'Rourke and Fraser, 1990). Thus, both the time interval and the area over which activity must be integrated to assess correlation will be significantly different between ipsilateral input elimination and topographic mapping in the optic tectum.

In the ferret LGN, NOS inhibition significantly reduces the sublamination of afferents into $\mathrm{ON}$ and OFF sublayers (Cramer et al., 1996). Sublamination is similarly reduced by NMDA receptor antagonists (Hahm et al., 1991). With these treatments, many retinal arbors lose their sublayer preference but do not increase in size. Thus, as in doubly innervated tadpole optic tecta, a direct, contralateral retinal projection displays arbor size maintenance and disorganization of arbor position in response to blockade of NMDA receptors. This is thought to arise from a disruption of the ability of the receptors to respond to coincident activity in converging synapses (Constantine-Paton et al., 1990; Cramer and Sur, 1995). However, in the ferret retinothalamic projection, the temporal patterning and the balance of activity among ON and OFF RGCs appear to be different from the activity that is involved in retinotopic mapping. During the period of LGN sublamination, ON bursts of action potentials, as measured by calcium imaging, are actually somewhat correlated with OFF bursts. Although the exact level of correlation among action potentials within $\mathrm{ON}$ and OFF bursts is unknown, it is clear that, for $\sim 75 \%$ of the time during sublaminar segregation, OFF RGC activity occurs while the ON RGCs are silent (Wong and Oakley, 1996). Thus, in the ferret LGN, as in the chick tectum, a diffusible, short-lived signal such as NO could cause retraction because one input is better correlated with the postsynaptic response than the other and the precise timing of transmitter release is not a critical factor in the response. Implicit in this idea is that, in either system, the remaining inputs must in some way be protected from retraction attributable to NO by their immediately preceding activity. The ON cell arbors in the LGN are presumably protected from complete elimination because they share activity correlations so that, once they segregate to zones of exclusive $\mathrm{ON}$ innervation, they are protected from the NO generated from their activity and distant from the NO generated in the OFF sublamina when they are silent. Cellular support for this hypothesis that NO mediates destabilization of less active inputs in instances of pronounced activity imbalance has been found in the in vitro neuromuscular junction preparation of Xenopus spinal neurons and myotubes. At these synapses, NO appears to be capable of mediating the functional suppression of silent axons, which have converged onto a myotube that is highly driven by another input (Wang et al., 1995). A similar functional suppression of inactive inputs does not occur at retinotectal synapses in Xenopus (Zhang et al., 1998).

Regardless of whether activity differences are the reason why $\mathrm{NO}$ is an effective signal in the refinement of certain projections but not others, the sensitivity of refinement to NOS inhibition correlates strongly with the developmental pattern of postsynaptic NOS expression. In both the NOS inhibitor-sensitive chick optic tectum and ferret LGN, NOS expression increases in a large proportion of the target neuron population during the relevant developmental period and decreases thereafter (Williams et al., 1994; Cramer et al., 1995). In contrast, in the mammalian cortex and in the tadpole optic tectum, NOS is expressed from very early developmental times in a low number of neurons dispersed in the tissue (Fig. 2) (Sandell, 1986; Kuchiiwa et al., 1994). Although developmental regulation of NOS is seen in neurons of the subplate and of layers V and VI of ferret visual cortex in which NOS inhibition has no effect on ocular dominance column formation, the postsynaptic neurons receiving the direct LGN afferent input in layer IV do not show pronounced NOS expression at any time (Finney and Shatz, 1998).

This report and those of others indicate that NO cannot be the sole retrograde messenger during activity-dependent developmental plasticity. In addition, the present results indicate that different signaling pathways mediating superficially similar, activity- and NMDA receptor-dependent structural changes in RGC terminal arbor patterning may be downstream of NMDA receptor activation. We suggest that alternative signaling systems may be necessary during activity-dependent synaptogenesis because of fundamental differences in the amount and the temporal patterning of the activity in the afferents that must compete and ultimately sort out during the establishment of CNS circuits.

\section{REFERENCES}

Ankri N, Legendre P, Faber DS, Korn H (1994) Automatic detection of spontaneous synaptic responses in central neurons. J Neurosci Methods $52: 87-100$.

Antonini A, Stryker MP (1996) Plasticity of geniculocortical afferents following brief or prolonged monocular occlusion in the cat. J Comp Neurol 369:64-82.

Bear MF, Kleinschmidt A, Gu Q, Singer W (1990) Disruption of experience-dependent synaptic modifications in striate cortex by infusion of an NMDA receptor antagonist. J Neurosci 10:909-925.

Blanton MG, LoTurco JJ, Kriegstein AR (1989) Whole cell recordings from neurons in slices of reptilian and mammalian cortex. J Neurosci Methods 30:203-210.

Bruning G, Mayer B (1996) Localization of nitric oxide synthase in the brain of the frog, Xenopus laevis. Brain Res 741:331-343.

Bruning G, Katzbach R, Mayer B (1995) Histochemical and immunocytochemical localization of nitric oxide synthase in the central nervous system of the goldfish, Carassius auratus. J Comp Neurol 358:353-382.

Burlet S, Cespuglio R (1997) Voltammetric detection of nitric oxide (NO) in the rat brain: its variations throughout the sleep-wake cycle. Neurosci Lett 226:131-135.

Cline HT, Constantine-Paton M (1989) NMDA receptor antagonists disrupt the retinotectal topographic map. Neuron 3:413-426.

Cline HT, Constantine-Paton M (1990) NMDA receptor agonist and 
antagonists alter retinal ganglion cell arbor structure in the developing frog retinotectal projection. J Neurosci 10:1197-1216.

Cline HT, Debski EA, Constantine-Paton M (1987) N-Methyl-Daspartate receptor antagonist desegregates eye-specific stripes. Proc Natl Acad Sci USA 84:4342-4345.

Cohan CS, Kater SB (1986) Suppression of neurite elongation and growth cone motility by electrical activity. Science 232:1638-1640.

Constantine-Paton M, Cline HT (1998) LTP and activity-dependent synaptogenesis: the more alike they are, the more different they become. Curr Opin Neurobiol 8:139-148.

Constantine-Paton M, Ferrari-Eastman P (1987) Pre- and postsynaptic correlates of interocular competition and segregation in the frog. J Comp Neurol 255:78-195.

Constantine-Paton M, Law MI (1978) Eye-specific termination bands in tecta of three-eyed frogs. Science 202:639-641.

Constantine-Paton M, Cline HT, Debski E (1990) Patterned activity, synaptic convergence, and the NMDA receptor in developing visual pathways. Annu Rev Neurosci 13:129-154.

Cramer KS, Sur M (1995) Activity-dependent remodeling of connections in the mammalian visual system. Curr Opin Neurobiol 5:106-111.

Cramer KS, Moore CI, Sur M (1995) Transient expression of NADPHdiaphorase in the lateral geniculate nucleus of the ferret during early postnatal development. J Comp Neurol 353:306-316.

Cramer KS, Angelucci A, Hahm JO, Bogdanov MB, Sur M (1996) A role for nitric oxide in the development of the ferret retinogeniculate projection. J Neurosci 16:7995-8004.

Crowe MJ, Brown TJ, Bresnahan JC, Beattie MS (1995) Distribution of NADPH-diaphorase reactivity in the spinal cord of metamorphosing and adult Xenopus laevis. Brain Res Dev Brain Res 86:155-166.

Cudeiro J, Rivadulla C, Rodriguez R, Martinez-Conde S, Martinez L, Grieve KL, Acuna C (1996) Further observations on the role of nitric oxide in the feline lateral geniculate nucleus. Eur J Neurosci 8:144-152.

Edelman GM, Gally JA (1992) Nitric oxide: linking space and time in the brain. Proc Natl Acad Sci USA 89:11651-11652.

Ernst AF, Wu HH, El-Fakahany EE, McLoon SC (1999) NMDA receptor-mediated refinement of a transient retinotectal projection during development requires nitric oxide. J Neurosci 19:229-235.

Fawcett JW, Willshaw DJ (1982) Compound eyes project stripes on the optic tectum in Xenopus. Nature 296:350-351.

Finney EM, Shatz CJ (1998) Establishment of patterned thalamocortical connections does not require nitric oxide synthase. J Neurosci 18:8826-8838.

Gally JA, Montague PR, Reeke Jr GN, Edelman GM (1990) The NO hypothesis: possible effects of a short-lived, rapidly diff usible signal in the development and function of the nervous system. Proc Natl Acad Sci USA 87:3547-3551.

Garthwaite J (1991) Glutamate, nitric oxide and cell-cell signalling in the nervous system. Trends Neurosci 14:60-67.

Garthwaite J, Charles SL, Chess-Williams R (1988) Endotheliumderived relaxing factor release on activation of NMDA receptors suggests role as intercellular messenger in the brain. Nature 336:385-388.

Gu QA, Bear MF, Singer W (1989) Blockade of NMDA-receptors prevents ocularity changes in kitten visual cortex after reversed monocular deprivation. Brain Res Dev Brain Res 47:281-288.

Hahm JO, Langdon RB, Sur M (1991) Disruption of retinogeniculate afferent segregation by antagonists to NMDA receptors. Nature 351:568-570.

Hickmott PW, Constantine-Paton M (1993) The contributions of NMDA, non-NMDA, and GABA receptors to postsynaptic responses in neurons of the optic tectum. J Neurosci 13:4339-4353.

Hickmott PW, Constantine-Paton M (1997) Experimental downregulation of the NMDA channel associated with synapse pruning. J Neurophysiol 78:1096-1107.

Hope BT, Michael GJ, Knigge KM, Vincent SR (1991) Neuronal NADPH diaphorase is a nitric oxide synthase. Proc Natl Acad Sci USA 88:2811-2814.

Hubel DH, Wiesel TN, LeVay S (1977) Plasticity of ocular dominance columns in monkey striate cortex. Philos Trans R Soc Lond B Biol Sci 278:377-409.

Ide CF, Fraser SE, Meyer RL (1983) Eye dominance columns from an isogenic double-nasal frog eye. Science 221:293-295.

Kantor DB, Lanzrein M, Stary SJ, Sandoval GM, Smith WB, Sullivan BM, Davidson N, Schuman EM (1996) A role for endothelial NO synthase in LTP revealed by adenovirus-mediated inhibition and rescue. Science 274:1744-1748.

Katz LC, Shatz CJ (1996) Synaptic activity and the construction of cortical circuits. Science 274:1133-1138.

Kleinschmidt A, Bear MF, Singer W (1987) Blockade of "NMDA" receptors disrupts experience-dependent plasticity of kitten striate cortex. Science 238:355-358.

Kuchiiwa S, Kuchiiwa T, Mori S, Nakagawa S (1994) NADPH diaphorase neurones are evenly distributed throughout cat neocortex irrespective of functional specialization of each region. NeuroReport 5:1662-1664.

Law MI, Constantine-Paton M (1981) Anatomy and physiology of experimentally produced striped tecta. J Neurosci 1:741-759.

LeVay S, Hubel DH, Wiesel TN (1975) The pattern of ocular dominance columns in macaque visual cortex revealed by a reduced silver stain. J Comp Neurol 159:559-576.

Lin SY, Constantine-Paton M (1998) Suppression of sprouting: an early function of NMDA receptors in the absence of AMPA/kainate receptor activity. J Neurosci 18:3725-3737.

Lohof AM, Quillan M, Dan Y, Poo MM (1992) Asymmetric modulation of cytosolic cAMP activity induces growth cone turning. J Neurosci 12:1253-1261.

Montague PR, Gancayco CD, Winn MJ, Marchase RB, Friedlander MJ (1994) Role of NO production in NMDA receptor-mediated neurotransmitter release in cerebral cortex. Science 263:973-977.

Nieuwkoop PD, Faber J (1967) Normal table of Xenopus laevis, Ed 2. Amsterdam: Elsevier.

O'Rourke NA, Fraser SE (1990) Dynamic changes in optic fiber terminal arbors lead to retinotopic map formation: an in vivo confocal microscopic study. Neuron 5:159-171.

Reh TA, Constantine-Paton M (1984) Retinal ganglion cell terminals change their projection sites during larval development of Rana pipiens. J Neurosci 4:442-457.

Reh TA, Constantine-Paton M (1985) Eye-specific segregation requires neural activity in three-eyed Rana pipiens. J Neurosci 5:1132-1143.

Reid SN, Daw NW, Czepita D, Flavin HJ, Sessa WC (1996) Inhibition of nitric oxide synthase does not alter ocular dominance shifts in kitten visual cortex. J Physiol (Lond) 494:511-517.

Rentería RC, Constantine-Paton M (1996) Exogenous nitric oxide causes collapse of retinal ganglion cell axonal growth cones in vitro. J Neurobiol 29:415-428.

Rioult-Pedotti MS, Rentería RC, Constantine-Paton M (1995) Nitric oxide enhances activity in the developing amphibian tectum. Soc Neurosci Abstr 21:818.

Ruthazer ES, Gillespie DC, Dawson TM, Snyder SH, Stryker MP (1996) Inhibition of nitric oxide synthase does not prevent ocular dominance plasticity in kitten visual cortex. J Physiol (Lond) 494:519-527.

Sandell JH (1986) NADPH diaphorase histochemistry in the macaque striate cortex. J Comp Neurol 251:388-397.

Scherer WJ, Udin SB (1991) Chronic effects of NMDA and APV on tectal output in Xenopus laevis. Vis Neurosci 6:185-192.

Sessa WC, Harrison JK, Barber CM, Zeng D, Durieux ME, D’Angelo DD, Lynch KR, Peach MJ (1992) Molecular cloning and expression of a cDNA encoding endothelial cell nitric oxide synthase. J Biol Chem 267:15274-15276.

Silberstein GB, Daniel CW (1982) Elvax 40P implants: sustained, local release of bioactive molecules influencing mammary ductal development. Dev Biol 93:272-278.

Son H, Hawkins RD, Martin K, Kiebler M, Huang PL, Fishman MC, Kandel ER (1996) Long-term potentiation is reduced in mice that are doubly mutant in endothelial and neuronal nitric oxide synthase. Cell 87:1015-1023.

Song H, Ming G, He Z, Lehmann M, McKerracher L, Tessier-Lavigne M, Poo M (1998) Conversion of neuronal growth cone responses from repulsion to attraction by cyclic nucleotides. Science 281:1515-1518.

Stryker MP, Strickland SL (1984) Physiological segregation of ocular dominance columns depends on patterns of afferent activity. Invest Ophthalmol Suppl [Abstr] 25:278.

Székely G, Lázár G (1976) Cellular and synaptic architecture of the optic tectum. In: Frog neurobiology: a handbook (Llinás R, Precht W, eds), pp 407-434. Heidelberg: Springer.

Taylor AC, Kollros JJ (1946) Stages in the normal development of Rana pipiens larvae. Anat Rec 94:7-23. 
Udin SB, Fawcett JW (1988) Formation of topographic maps. Annu Rev Neurosci 11:289-327.

Udin SB, Scherer WJ, Constantine-Paton M (1992) Physiological effects of chronic and acute application of $N$-methyl-D-aspartate and 5-aminophosphonovaleric acid to the optic tectum of Rana pipiens frogs. Neuroscience 49:739-747.

Wang R, Xie Z, Lu B (1995) Nitric oxide mediates activity-dependent synaptic suppression at developing neuromuscular synapses. Nature 374:262-266.

Williams CV, Nordquist D, McLoon SC (1994) Correlation of nitric oxide synthase expression with changing patterns of axonal projections in the developing visual system. J Neurosci 14:1746-1755.
Wong RO, Oakley DM (1996) Changing patterns of spontaneous bursting activity of on and off retinal ganglion cells during development. Neuron 16:1087-1095.

Wu HH, Williams CV, McLoon SC (1994) Involvement of nitric oxide in the elimination of a transient retinotectal projection in development. Science 265:1593-1596.

Yen L, Sibley JT, Constantine-Paton M (1995) Analysis of synaptic distribution within single retinal axonal arbors after chronic NMDA treatment. J Neurosci 15:4712-4725.

Zhang LI, Tao HW, Holt CE, Harris WA, Poo M-M (1998) A critical window for cooperation and competition among developing retinotectal synapses. Science 395:37-44. 